\title{
THE NEW EMERGENT MULTIMEDIA CONTENT AND DIGITAL RIGHTS MANAGEMENT
}

\author{
Jeferson de CARVALHO \\ Faculdade Casper Libero, Master in Mediatics Process, Sao Paulo, Brazil \\ jefersondecarvalho@gmail.com
}

\begin{abstract}
Culture in the digital environment, after a drastic reduction in the cost of storage and editing, allowed remixing and faster sharing than in the analog age. The result of this new content is no longer published or presented through traditional forms known in the analog era. The old gatekeepers are no longer gatekeepers. Thus, copyright, once valid, conflicts with the dynamics of the digital culture. Digital Rights Management, used by a company as a tool, is an option to control and to guarantee economic interests. How can it become sustainable in order to create, to consume, to publish and to share multimedia content in this landscape?
\end{abstract}

Keywords: Technology, Communication, Multimedia, Social Network.

\section{INTRODUCTION}

The goal of this paper, from an Information Economy perspective, is to start defining the Information Network as a product of Technology Network (Internet). The Information Network is a body of content that flows through the Technology Network carrying its inherited characteristics. The topology of this network allows a more democratic practice of speech and access to information.

Regulated process during the analog age is not long valid under a digital contemporaneity, where copyright laws have been replaced by digital copyright laws. And this scenario, with a combination in a digital environment, - where social relationships are improving connections, banning hierarchy, - the digital copyright could set a limit to the Information Network.

Adding a perspective about Information Economy, in the digital era, where Information can be transformed into a marketable and marketed commodity with little invasion of privacy, technology makes it possible to monitor, record and restrict what people are looking at, listening to, reading, and hearing. This is the context where the development of hermetical packages of software and hardware appears, and thus the Digital Rights Management (DRM). There is no point in delving into issues of surveillance, or expanding the scope of the context of copyrights laws - analog copyright or digital copyright. This paper limits copyright to a form of protection provided by laws including literary, dramatic, musical, artistic and certain other intellectual works. It is a flexible instrument and it has often had to make adaptations to accommodate the effects of changing times, places and technologies. Digital copyright increased the penalties for copyright infringement on the internet and online service providers.

Finally, this article, supported by contemporary authors who explore Network issues, such as Barabási, Newman, Kleinberg and Wasserman, authors with a view about the power of user generated content such as Benkler, Castells, Jenkins and a commercial and regulator perspective such as Lessig, Wu, Anderson and Galloway, will embrace the culture in the digital environment and its disruptive behavior deriving to a new type of content creators that avoid gatekeepers, create their own forms of dissemination, and share it through Connected Social Networks Sites. All these predicates conflict with the dichotomous decision to adopt DRM by news companies, publishers, broadcasters and retailers.

\subsection{From The Technology Network To The Information Network}

The Internet is a prime example of a Technology Network that is technically a global network connected via cable, satellite and fiber that connects computers and systems. Through the 
Technology Network, information packets are sent and received, complying the Internet protocols ${ }^{1}$.

Interaction on the Internet is not bureaucratic and not hierarchical, quite often packages have been lost owing to the failure of hardware or software, which contributes to the misconception that the Internet is chaotic rather than highly controlled ${ }^{2}$.

The characteristics of "nodes" and "edges" of computers and physical connections between them exemplify how the Internet is a Technology Network. Although most computers have a single connection to the Internet, they are connecting with Internet service providers (ISPs) that are hubs, which in turn connect to regional distributors (usually telecommunications companies) that are interconnected globally through major backbones (NBPs).

The web - acronym for World Wide Web or www - is browser layer, which Tim Berners-Lee was largely responsible for its creation and triggering a variety of software and applications. The web is an Information Network. The nodes are the web pages of each site, and the edges are the hyperlinks that are underlined texts that pull or carry the navigation between content rendered in other web pages. A hyperlink is a type of software.

"Software, of course, is what organizes the Internet, routing email messages, delivering web pages from a server, switching network traffic, assigning IP addresses, and rendering Web pages in a browser." (Manovich,2008:7)

Since users begin to add hyperlinks between their content pages to the web structure it revels patterns of this system. The more hyperlinks associated with content, the higher this page's relevance. This is a basic concept used for semantic engineering searches on the internet ${ }^{3}$.

"As the RFC on Transmission Control Protocol simply defines it, hosts are "computers attached to a network." If the host is a receiver of information, it is called a client. If it is a sender of information, it is called a server." (Galloway,2004:66)

The topology of the Technology Network consists of connections without hierarchy, allowing a stream of information to flow, creating an Information Network, which in turn inherits its flexible features and no complications. The software, within the Information Network on the web, allows the creation of applications, which accumulates information repositories that become content. Users, in turn, posting and consuming this content, create a flow, a mainstreaming. However, some of those hubs of content flow accumulate more than others and do not follow an equilateral proportion, and thus the figure of the gatekeeper appeared.

"Social actors may establish their power position by constituting a network that accumulates valuable resources and then by exercising their gatekeeping strategies to bar access to those who do not add value to the network or jeopardize the interests that are dominant in the network's programs." (Castells,2011:43)

Information, as structural data, itself becomes Content ${ }^{4}$. The Information Economy is based on the cost or on the creation of its added value, and determines its value from the effort of psychological mechanisms and mechanics as imposed for its acquisition in such relevant situations. The flows are created in the Information Network between the nodes, circulating through various communication channels between these nodes. The content in this context is structured data, moving from one network technology-laden information, constituting a data network, forming informational flows.

"In the networked information environment, everyone is free to observe, report, question, and debate, not only in principle, but in actual capability." (Benkler,2006:272)

An Information Network based on the Technology Network triggered a new model of 
Information Economy, the Information Network Economy, based on intangibles, where cheap processors with high computational capabilities interconnected transformed the economy to an immaterial environment and highlighted the communication. Therefore, the potential of Networks is essential for the formation of society.

\subsection{The Information Network Economy}

The advent of new technologies was an important factor in the change in the economic model for the twenty-first century from the atom to bits. This changed the economic relationship from analog to digital. New market opportunities began to emerge, breaking down the barriers of distance and logistics, enhancing ignored markets, reanalyzing the relationship between cost and outreach ability, application analytical filters, and reducing the distortion of breadth and depth equation for all nodes in the chain, characterized by suppliers, intermediaries and consumers ${ }^{5}$.

This new economy model is about the interpretation of data structures. The Internet had its taxonomy from the organized event called Black Hub Project when Google made a copy of all files on the network to order them ${ }^{3}$. This reinforces the triggering event, approached by Floridi. In his definition, the "data" (structured) becomes - or can be interpreted as "content", and it then becomes "information" ${ }^{4}$.

The software added features as commercial transactions within a harmonic architecture, reflecting in the digital environment the supply law breaking the constraints of physical shelf space and of other distributions bottlenecks, goods and services could economically attractive to all those general public. ${ }^{5}$. It is a scenario where physical distances and time zone were replaced by clicks, the concept of uninterruptibility moved the work to another dimension, but the bureaucracy, inflexibility and lack of scalability are factors that affect the efficiency of collective participation as proves the rule on participation ${ }^{6}$.

There is no distance or limited production and distribution in the Information Network Economy. The reduction of costs was, without doubt, the key to a large-scale change. The digital age provides accessibility to Informational Network, which, filled with content embedded in web applications, highlights Connected Social Networks Sites ${ }^{7}$. Due to more affordable mass technology, and decentralized individual action, the content publication and the its consume do not follow the mainstream standard. The gatekeepers no longer play the role of gatekeepers. The old hierarchies give way to a decentralized topology.

\subsection{The Connected Social Network Sites And The Remix Culture}

The networks are under development, and may or may not evolve; changing the environment within a network directly affects its participants, who may or may not adapt to it. The web as a medium is so flexible that it makes choices for us $^{8}$. The Connected Social Networking Sites have being changing over time and not always what we originally were born to, any Connected Social Network Site has this characteristics. They represents intrinsic theirs owners mind set.

It is essential to analyzing the new society configuration characterized by the presence of the web, because this same society, during the analog ages, it was not conducive for sharing. The analog content was read only, (RO). A copy made from the analog content was inferior to the original, and the technologies available to allow these copies were scarce.

Antagonistically, digital content has become read and write (RW), taking advantage of the reduced cost of digitization, as well as technological change, new facilities for communication and content sharing. However, the RW culture is not limited to easy digitization and sharing, since the remix is the feature that stands out, driving and being driven by the creativity of new customers. That is, Remix is an essential act of RW creativity. It is the expression of a freedom to take the songs of the day or the old songs and create with 
them ${ }^{9}$.

Lessig highlights the existence of the Remix behavior in both cultures. However, the code, (patterned relationships to identify, authenticate and accredit), is closed and limited in the RO culture and flexible and very available in the RW culture. People have not more remix culture in the digital era, indeed, the RW code, and in the digital age, allows to remix it more.

RW culture brought about disruptions in economic models practiced by content providers, lack of control over the origin and distribution. The Code of RW culture does not respect the conduct of the real space. It is not a disentangled situation between the software application and the tactical control.

\subsection{Digital Right Management And Multimedia Content Issue}

Encapsulating digital content through a software code and systems was the solution to rewrite the business models and guarantee the capability to control and specify the rights associated with this content. This solution is called Digital Rights Management, (DRM), which complements all conditions of any digital content only associated with a particular application. Building upon this paradigm, the DRM can associate the content, and application equipment (hardware) with the technology that protects against unauthorized access and usage and which enforces the restrictions on what users can do with it.

"Multiple Access-Control technologies appeared under the name of "electronic rights management systems" in 1995, and commercial systems appeared early in 1996. Yet, in the spring of 2000, several generations later in Internet time, record companies had failed to secure their recording, or to make them available for digital download." (Litman,2001)

From an Information Economy perspective, the imprisonment of content, application and equipment may maximize economics results in the consumer electronic market, specially to pure hardware company. Therefore, setting a hermetic possibility to the RW culture, it is to approaching, paradoxically, to the RO culture.

"DRM is predominantly an economic mechanism, which owes its very existence to the fact that content businesses rely on their ability to generate revenue from the replication and distribution of content, and that any enabler of these abilities is also a potential conduit for content leakage and a consequent loss of revenue." (Umeh,2007)

Since DRM is a tool and its main objective is to improve content monetizing it has the ambition to control usage and access in the digital environment and also outside it. So it handles a complete package of features to different types of media such as copy protection, access control, embedded algorithms to cryptography and rights managements; deriving into a complex ecosystem basically made up of a triad of Content, User and DRM Features. It does not work in isolation.

Some DRM characteristics could be interpreted as issues, for example, manufacturers can embed different cryptographic codes into their devices making the content interoperable when switched into devices, once DRM works with a three piece interconnected the portability concept cannot be always applied, there is no way to prevent anyone from capturing digital output and re-encoding this into a unprotected digital format, perceived by some users of an anti-piracy tool than an new content business model, and the DRM implementation is not invisible to the user.

An additional limitation to DRM is software that can copy DRM-protected files, such as Tunebit 6, Noteburner 2, SoundTaxi 3, MuvAudio2 and AppleMacSoftware DRM Converter $2^{10}$. Besides, a manufacturer can choose to replace its own DRM making its own content incompatible as Microsoft did after launching its iPod killer Zune ${ }^{11}$, leaving behind the 
PlayForSure DRM. Apple runs FairPlay DRM, both are interoperable. On 6 January 2009 Apple announced at the 2009 Macworld Conference \& Expo that they had reached an agreement with major record labels to sell all music on the iTunes Store free of DRM restrictions ${ }^{12}$. However, movies, books and television shows purchased from the iTunes Store still contain FairPlay restrictions.

"Ur-free and free software beloved of tech geeks. By giving away a version adapted for telephony, Google was distributing a free set of tools for programmers of any affiliation to write applications". (Wu,2010:294)

An example about respect digital copyright and be profitable playing DRM free is a couple of musicians called Pomplamoose ${ }^{13}$. They bought secure rights to cover other artists' songs and got money selling their own DRM free songs through over Amazon MP3 and Apple's iTunes $^{14}$.

Contradictorily, new DRM initiatives are still on, as so over the video and the e-books industry. Amazon, the first music DRM-free gatekeeper, announces its iPad-killer Kindle Fire running under a customized platform. And Associated Press and another 28 publishers announce a new start-up company called Newsright that will measure the unpaid online use of their original reporting and seek to convert unauthorized websites, blogs and other newsgathering services into paying customers ${ }^{15}$.

\section{CONCLUSION}

Digital media flowing through a network connection is the most democratic of media, promoting free expression and access to information wherever a computer can be hooked up. The revolution from analog to digital is, in fact, a confrontation of the contemporary economic model. The RW culture delivers everything so simply, the user has control, no rules, remixed, creative and non-linear. However, digital copyright owners are in a position to claim exclusive "reading", "listening" and "viewing" rights.

It is a controversial scenario; the web facilitates interaction between users, but some technology companies simultaneously seek to limit access to information and imprison the consumer - especially for economic reasons- particularly by DRM use, as a digital copyright tool. From the user's perspective, paradoxically, it must surrender to the tightness even under the flexibility of digital networks, arranged by the rules of commercial gatekeepers.

However, users want to play their content anywhere, any time on any device and DRM owns its defects, besides it already has been jailbreaked. The old gatekeepers are no longer gatekeepers, they have kept them out in the past because users of the Information Network, with great capacity to acquire structured information -, escape the snares applied with the commercial purpose, from the DRM tools and seek alternative ways.

Although DRM was designed to be a commercial application to increase digital copyright revenue, it has been abandoned by the main gatekeepers, at least in the music industry, not because a new economic model emerged but because the attempt to be complete left it static and incompatible with the dynamic and decentralized architecture of the digital age.

Pure DRM, with its weakness, is not the only alternative anymore, and the real opportunity for the old gatekeepers is in the platforms. Gatekeepers do not control the Network, do not control users, and cannot apply a hermetic content. However, they can create their own environment in a customized digital platform combining software and hardware, where the content itself is DRM free. DRM is not a solution to avoid conflict with economic interests nor is it a barrier to create, remix and share multimedia content, but digital copyright is still an issue and news companies, publishers, broadcasters and retailers are looking forward to new perspectives. 


\section{REFERENCES}

[1] Newman, M.(2010).“The empirical study of networks' Networks, an Introduction, New York: Oxford University Press.

[2]Galloway, Alexander R.(2004). Protocol: How Control Exists after Decentralization. Cambridge: MIT Press.

[3]Easley, D.; Klenberg J.(2010). Networks, Crowds, and Markets: Reasoning About a Highly Connected World, Cambridge University Press.

[4]Floridi, L.(2010). Information - A Very Short Introduction. New York: Oxford University Press.

[5]Anderson, C.(2006). A Cauda Longa. Do Mercado De Massa Para O Mercado De Nicho. Rio de Janeiro: Elsevier.

[6]Nielsen, J.(2006)."Participation Inequality: Encouraging More Users to Contribute". http://www.useit.com/alertbox/participation_inequality.html [10/11/2011].

[7]Lima, JR.(2009)."Mídia social conectada: produção colaborativa de informação de relevância social em ambiente tecnológico digital”. Libero, (24): 95-106.

[8]Berners-Lee, T; FischettiI, M.(2000) Weaving the web: the original design and ultimate destiny of the World Wide Web, by its inventor. New York: HarperCollins Publishers.

[9]Lessig, L.(2008). Remix: Making Art and Commerce Thrive in the Hybrid Economy. New York: The Penguin Press.

[10]Harris, M.(2008).“Top 5 DRM Removal Programs.The best software for removing DRM protection from your media files."

http://mp3.about.com/od/essentialsoftware/tp/best_drm_removal_software.htm [10/12/2011]. [11] Wired.(2006). "Screwed for Sure."

http://www.wired.com/entertainment/music/commentary/listeningpost/2006/08/71621

[10/12/2011].

[12]BBC NEWS (2009). "Apple to end music restrictions"

http://news.bbc.co.uk/2/hi/technology/7813527.stm [10/12/2011].

[13] Simple Music Contracts.(2011). "Pomplamoose Music License."

http://www.simplemusiccontracts.com/pomplamoose-music-license [10/12/2011].

[14] Always More To Hear.(2009). "A case study of Pomplamoose: 10 tips to be a successful internet musician". http://www.alwaysmoretohear.com/2009/12/pomplemoose-case-study-inbeing.html [10/12/2011].

[15] The Washington Post.(2012). "NY Times and others launch Newsright on line clearinghouse". http://www.washingtonpost.com/business/ap-nytimes-mcclatchy-otherslaunch-newsright-online-rights-clearinghouse [10/1/2012].

[16] Barabasi. A-L.(2010). Bursts: the hidden pattern behind everything we do, Dutton.

[17] Benkler, Y.(2006).The wealth of networks: how social production transforms markets and freedom. New Haven and London: Yale University Press.

[18] Jenkins, H.(2009). Cultura da convergência. São Paulo: Aleph.

[19] Knoke, D.; YANG S.(2008). Social network analysis - Quantitative applications in the social science, $\mathrm{SAGE}$.

[20] Lessig, L.(2010). Code 2.0. New York: SoHo Books.

[21] LitmanI, J.(2001). Digital Copyright. New York, Prometheus Books.

[22] Manovich,L.(2008). Software takes command.

http://softwarestudies.com/softbook/manovich_softbook_11_20_2008.pdf [22/09/2010].

[24] Wasserman, S.; FAUTS K.(1994). Social Network Analysis - Methods and Applications. Cambridge University Press.

[25] WU, T.(2010). The Master Switch. The Rise and Fall of Information Empires. New Tork: Alfred A. Knopf. 